\title{
"O potro do Estado": \\ O retrato de Maria Luísa de Parma \\ por Goya e a tradição de retratos \\ equestres na Espanha e Europa
}

\author{
Francisco Fontanesi Gomes \\ DOI 10.20396/eha.vil4.3356
}

O artista espanhol Francisco de Coya y Lucientes (1746-1828) possui uma vasta produção artística e muito diversa, pela qual é lembrando como um dos principais artistas da história espanhola. "Don Paco"z se concentrou na produção de diversos temas e gêneros da pintura. Nas décadas de 1780 e 1790. Coya possuía uma carreira invejável, recebia encomendas de diversos nobres e príncipes da casa real, inclusive do rei Carlos III. Suas conexões com Francisco Bayeu (1734-1795) e Anton Raphael Mengs (1728-1779) Ihe garantiram uma oportunidade de demonstrar sua habilidade diante da corte espanhola, inclusive de conseguir as encomendas dos Cartones para Tapices (1775-1792), uma série de pinturas temáticas destinadas a se tornarem tapeçarias para decorar os prédios oficiais do Estado espanhol, bem como diversos palácios reais. Essa foi uma das portas de entrada que garantiu ao artista aragonês um reconhecimento dos reis espanhóis e que o levará a pintar os retratos destes. É importante notar evidência do envelhecimento (seja ele tardio ou precoce em seus modelos) e rostos considerados "feios" ou incomuns por diversos historiadores da arte - vide Combrich ${ }^{3}$ ou Robert Rosemblum; ${ }^{4}$ essas características podem ser interpretadas como confirmações de uma sátira velada que o artista fazia aos seus patronos, como o próprio Peter Burke aponta como uma questão em sua obra, Testemunha Ocular:

"Em segundo lugar, as convenções do gênero possuem um propósito: apresentar os modelos de uma forma especial, usualmente favorável - embora a possibilidade de que Coya estivesse satirizando os modelos em seu famoso Carlos IV e família (1800) não deva ser esquecida."

Por essa passagem, é possível perceber que apesar da regra ser a de disfarçar "deformida-

\footnotetext{
1 Aluno do programa de Pós-graduação em História da Arte da Unifesp com projeto orientado pela Prof. ${ }^{a}$ Dr. ${ }^{a}$ Elaine Dias. É formado em História pela Unesp FCL de Assis-SP.

2 Apelido comumente utilizado para se referir a Coya, como afirma Tzevetan Todorov em seu livro Goya: à sombra das luzes.

3 COMBRICH, 2012, p. 487 e 488.

4 ROSEMBLUM, 2004, p.152 e 153.

5 BURKE, 2017, p. 43.
} 
des", ainda é possível questionar os retratos de Goya e as intenções do artista em pintar seus modelos (em especial, seus rostos) dessa forma "incomum". Para promover essa discussão e procurar por outros elementos que não apenas o feio, o texto irá se concentrar em um dos retratos mais icônicos produzidos por Goya e de uma das modelos mais intrigantes pintada pelo artista: O retrato equestre da rainha Maria Luísa de Parma (La reina Maria Luísa de Parma a caballo; Museo Nacional del Prado, 1799, figura 1). Na tela, uma das poucas a retratar mulheres montando em cavalos ${ }^{6}, a$ principal personagem mostrada é a rainha Maria Luísa de Parma, que, junto com seu marido e primo, Carlos IV, reinou entre 1788 até 1808. Apesar de ter tido uma educação iluminista, Maria Luísa sempre foi vista como uma das representantes do Ancién Regime espanhol. Junto da mulher de seu primo francês, Maria Antonieta, era tida como uma rainha despótica, uma estrangeira que se infiltrou no governou de seu marido e promoveu seus favoritos, como o Valido Manuel de Godoy. Sua relação com Godoy foi tão mal vista que era tida como sua amante e assim como sua contraparte francesa, a rainha era vista como uma mulher devassa, cheia de amantes, lasciva, enquanto seu marido era controlado por seu gênio forte e não tinha qualquer interesse nos afazeres do Estado7 . É importante frisar que muitas dessas acusações são consideradas rumores exagerados e um período de grande ebulição política contra as monarquias europeias: o período pós-Revolução Francesa. O que é possível afirmar como consenso é que a rainha italiana teria uma influência inegável dentro da vida política na corte espanhola, mesmo antes de se tornar a rainha de fato. Quando princesa de Asturias, sua sogra havia morrido cedo e dentro dos protocolos reais, isso a tornava a principal dama da corte de Carlos III, o que deu a rainha um papel de maior relevância. O professor Antonio Maturana destaca essa influência como um consenso historiográfico e como essa foi uma das razões que o ministro Ilustrado de Carlos III, o conde de Floridablanca acabou perdendo influência no governo de Maria Luísa e Carlos IV em benefício de Manuel de Codoy ${ }^{8}$ Logo depois de Carlos e Maria Luísa assumirem o trono, no ano de 1789, eclode a Revolução na França, basicamente quebrando o poder do principal ramo da casa Bourbon na Europa. Em 1793, o rei Luís XVI é guilhotinado, seguido de sua mulher, Maria Antonieta. Da rainha francesa, sobrou um esboço (figura 3) importante produzido por Jacques-Louis David (1748-1825). Esse esboço mostra a completa fragilidade de Maria Antonieta, sem qualquer pompa ou decoro de seus retratos oficiais, prestes a ir ao cadafalso. É nesse contexto histórico de fragilidade das monarquias europeias e de suas imagens que o retrato de Maria

\footnotetext{
6 Existe outro retrato equestre de uma mulher feito Goya, o de Maria Teresa de Villabriga (figura 2)

7 HARGREAVES-MAWDSLEY, 1979, p. 110

8 MATURANA, 2010, p. 121-130.
} 


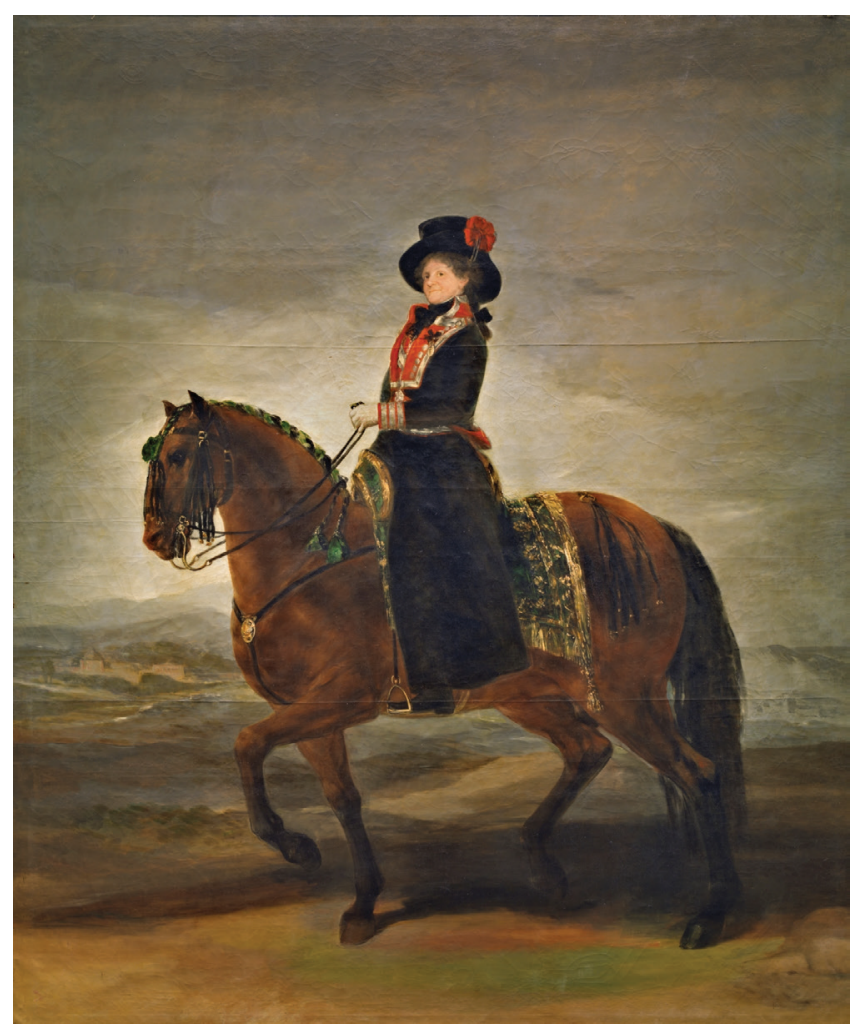

[Figura 1] Francisco de GOYA y Lucientes. La reina María Luisa a caballo, 1799.

Óleo sobre tela, 338 × $282 \mathrm{~cm}$. Museo Nacional del Prado, Madrid.



[Figura 3] Jacques-Louis DAVID. Marie Antoinette on her way to the guillotine, 16 de outubro de 1793.

Naquim sob papel, $150 \times 100 \mathrm{~mm}$. Museé du Louvre, Paris.

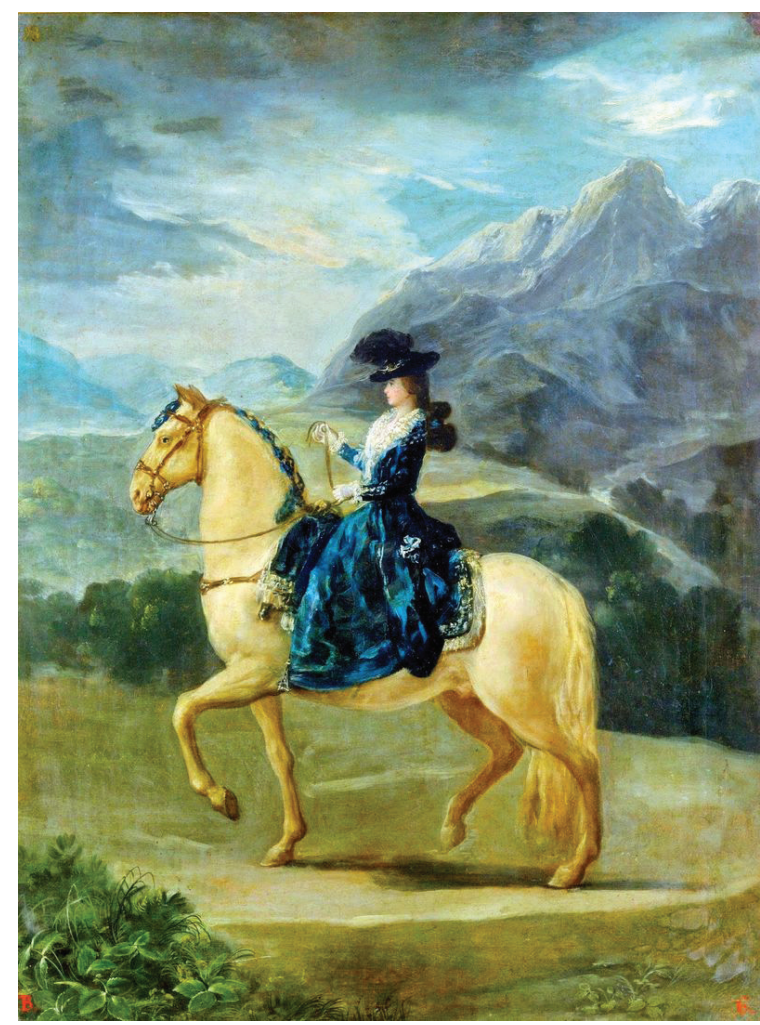

[Figura 2] Francisco de GOYA y Lucientes. Maria Teresa de Villabriga a caballo, 1783.

Óleo sobre painel de madeira, $82,5 \times 61,7 \mathrm{~cm}$. Calleria degli Ufizzi, Firenze.

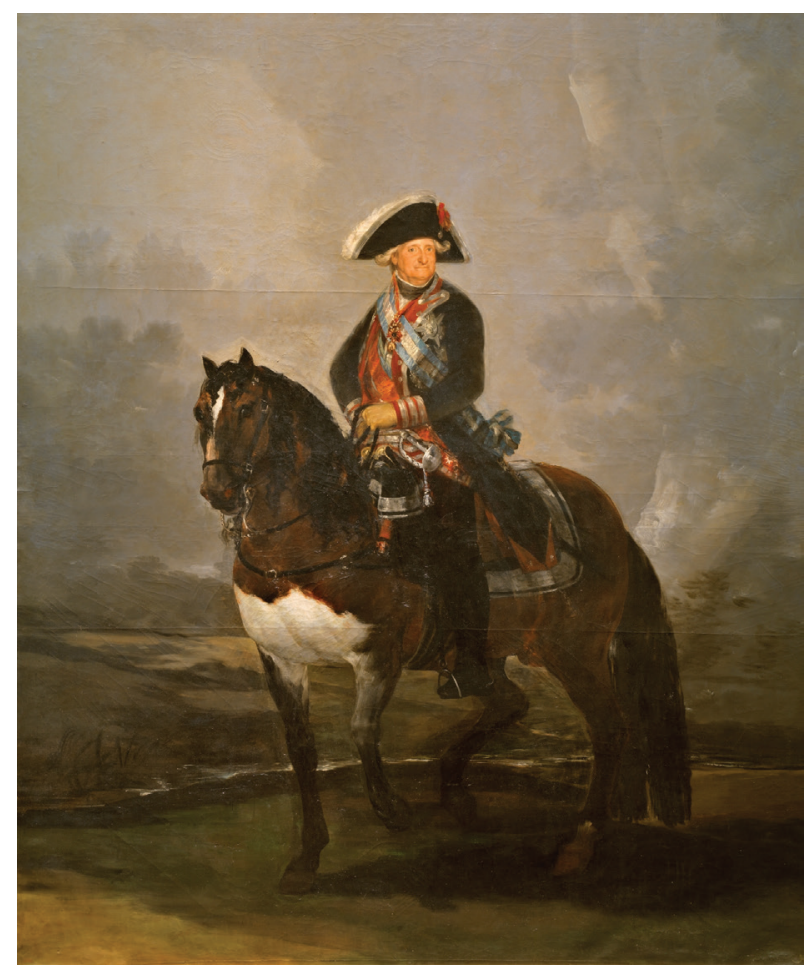

[Figura 4] Francisco de GOYA y Lucientes. Carlos IV a caballo, 1800 .

Óleo sobre lienzo, $336 \times 282 \mathrm{~cm}$. Museo Nacional del Prado, Madrid 
Luísa se encontrava.

Com os acontecimentos políticos cada vez mais intensos a experiência da doença que atingiu entre 1792 e 1793, Goya continuava, contudo, a se dedicar a arte, tanto dentro como fora do sistema de corte. É nesse momento delicado que o retrato de Maria Luísa é produzido. Seu retrato é de grandes proporções, com mais de três metros de altura, assim como vários retratos equestres de príncipes europeus. Um dos primeiros elementos a serem destacados na descrição da obra é a própria figura da Rainha. Ela se encontra montada em seu cavalo preferido, Marcial, que foi um presente de seu Valido Codoy ${ }^{9}$. Diferente das rainhas velasqueñas, a rainha Bourbon monta seu cavalo com as pernas abertas e não sentada com as pernas cruzadas e cobertas. Além disso, Maria Luísa também é vista trajando um uniforme militar, mais especificamente da Guardia de Corps, um regimento militar espanhol de elite. Este tipo de pintura equestre com o uniforme militar é normalmente reservado às figuras masculinas; aqui, porém, a rainha parece não apenas com trajes e posições militares, mas com um uniforme militar adaptado ao gênero feminino - vide as diferenças com o retrato equestre de seu marido (figura 4), que usa o uniforme do mesmo regimento. A rainha também segura as rédeas de seu cavalo sem se esforçar muito, mas com certa firmeza e, em sua mão, faz uso de luvas brancas, um dos símbolos da aristocracia ${ }^{10}$. Neste momento, é importante frisar a importância simbólica desse gênero de retrato de corte. Este tipo de retrato sempre foi associado à guerra e a figuras masculinas, mas também servia como um tipo de metáfora para o controle que o monarca exercia sobre o governo, como aponta Burke sobre os retratos equestres de Velázquez:

\footnotetext{
"Outra metáfora antiga para simbolizar domínio é a do cavalo e do cavaleiro (...) Pode ser esclarecedor justapor essa pintura com um tratado espanhol de 1640 sobre pensamento político, Ideia de um príncipe cristão, de Diego Saavedra Fajardo que desenvolve a metáfora recomendando ao príncipe "domar o potro do poder", por meio de "um tanto de vontade (...) do freio da razão, das rédeas da política, da chibata da justiça e da espora da coragem”, e, acima de tudo, dos "estribos da prudência."11
}

Neste trecho, o autor deixa claro o poder simbólico que o retrato equestre carrega na Espanha, em pleno século XVII, período em que Velázquez pintou seus famosos retratos equestres dos Habsburgo. Apesar das diversas inovações que Coya traz ao retrato - tendo em vista a própria posição da rainha, o seu rosto envelhecido, mas que contém um leve sorriso convencido (talvez o pri-

\footnotetext{
9 HUGHES, 2007, p. 282.

10 SCHINEIDER, 1997 p. 128.

11 BURKE, 2016, p. 96.
} 
meiro sorriso na pintura de corte de uma personagem real espanhola) - é possível traçar diversos paralelos com modelos e referências de antigos mestres, tanto espanhóis como de outras regiões da Europa. É interessante notar que esse modelo equestre de um líder ou príncipe montando um cavalo e trajando seu uniforme militar pode ser rastreado até a estátua equestre do imperador romano Marco Aurélio ${ }^{12}$ (Museu dos Capitolinos, 161-180 d.C.); mas ela realmente se firma como um modelo a ser seguido, porém, a partir do retrato equestre que Tiziano (1477/90-1576) produz do Imperador Habsburgo, Carlos V (figura 5). Diversos elementos vão continuar a ser perpetuados, vide o uso da armadura e de condecorações que aludem ao arquétipo de cavaleiro cristão, como o colar da ordem do tosão de ouro usada pelo imperador. Outros elementos, como uma floresta ou uma paisagem montanhosa ao fundo já começam a aparecer nesse retrato, que representa o imperador alemão e rei espanhol na batalha de Mühlberg, onde este obteve uma grande vitória contra os príncipes protestantes do Sacro Império Romano, sendo considerado por Hans Vlieghe como "o mais influente retrato equestre renascentista de um monarca vitorioso"13. E por ser rei da Espanha "unificada", o primeiro Habsburgo, com certeza o retrato do imperador devia ser visto como um modelo a ser seguido pelos monarcas Bourbons, como afirma Enrico Castelnuovo sobre o refinamento que Tiziano atingiu ao representar Carlos $V$ nesse retrato equestre ${ }^{14}$.

Outro elemento importante no retrato de Maria Luísa é a paisagem. É possível observar em segundo plano um grande céu acinzentado acima de uma região montanhosa, com uma leve claridade envolta do corpo da rainha. O chão sobre o qual Maria Luísa cavalga possui tons marrons e claros, mas ao mesmo tempo possui um tom esverdeado, mas sem vegetação. É importante frisar dois elementos no plano mais ao fundo, um à direita e outro à esquerda do quadro. É possível observar à esquerda um tipo de construção, parecida com um tipo de casa de casa ou um pequeno palácio que não parece muito bem definido pelos traços do artista. Essa construção é identificada como o palácio real de la Granja de San Ildefonso. É importante notar que este palácio foi construído por seu avô, Felipe $\mathrm{V}$, aos moldes de Versalhes, como um retiro para a família na região de Segovia, a algumas horas da cidade Madri. Apesar de não estar tão bem definido, os tons amarelos e claros permitem identificar a real Cranja, que pode ser considerada um símbolo da dinastia dos Bourbons, marcando sua chegada na Espanha, sobretudo se comparada à construção que se encontra no canto direito do quadro. É possível observar outra construção, dessa vez muito mais cinza e difícil de identificar,

\footnotetext{
12 SCHINEIDER, 1997, p. 27, 28.

1314 VLIEGHE, 2001, p. 134.

14 CASTELNUOVO, 2006, p. 56-61.
} 


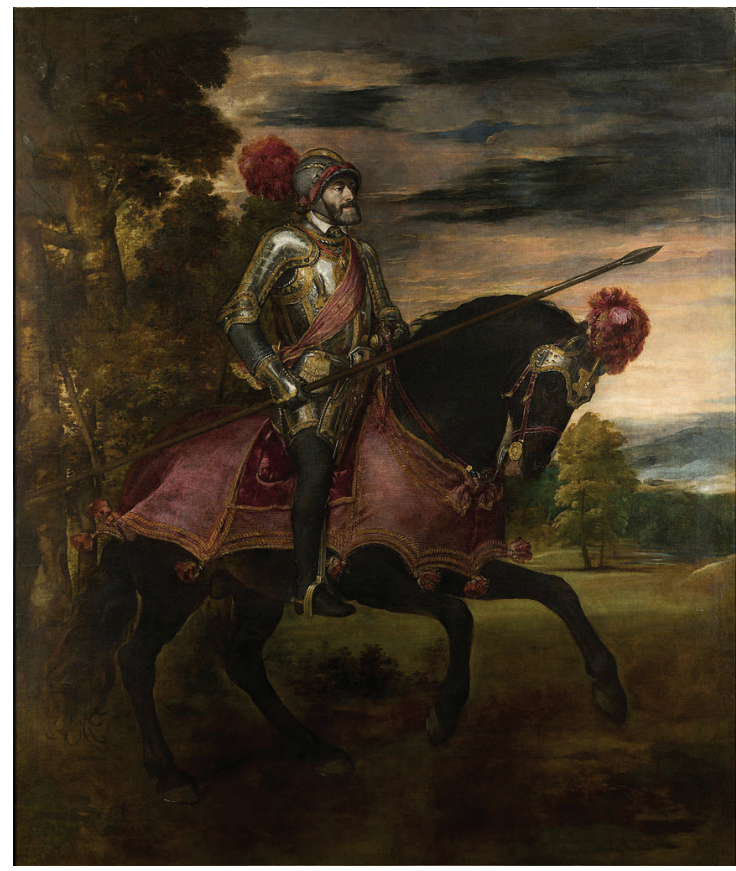

[Figura 5] Vecellio di Gregorio TIZIANO. Carlos V en la Batalla de Mühlberg, 1548.

Óleo sobre tela, $335 \times 283 \mathrm{~cm}$. Museo Nacional del Prado, Madrid.

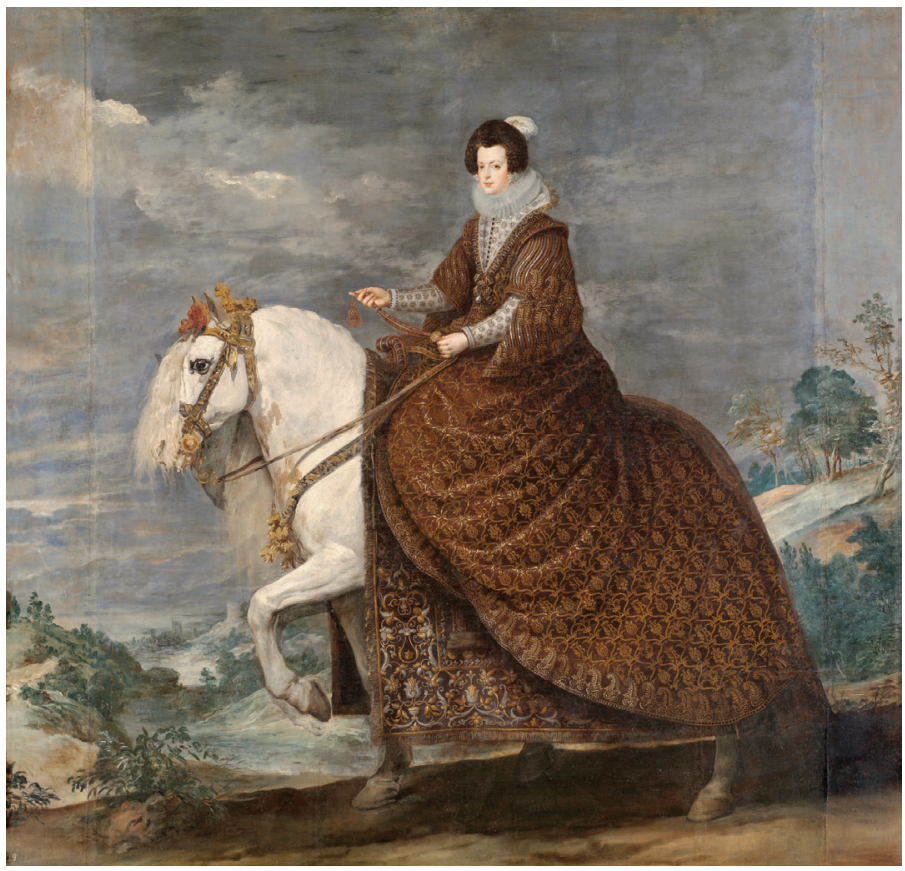

[Figura 6] Diego Rodríguez da Silva y VELÁZQUEZ. La reina Isabel de Borbón, a caballo, 1635.

Óleo sobre tela, 301 × 314 cm. Museo Nacional del Prado, Madrid.

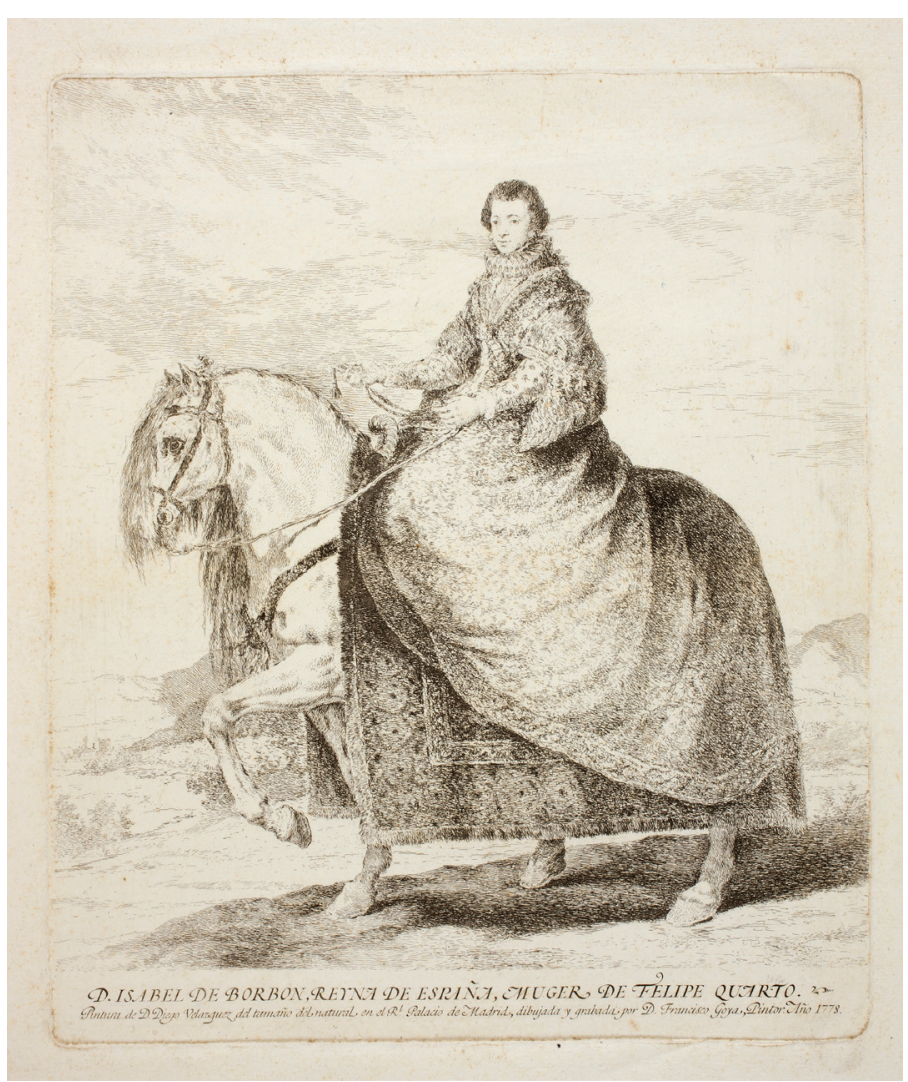


mas que parece mais velha e malcuidada, dando outra impressão ao espectador. Essa é, na verdade, uma representação do palácio de Valsaín, que fica a alguns minutos de San Ildefonso. Neste palácio do período Habsburgo, ocorreu um grande incêndio que o deixou em ruinas 1682, e nunca houve uma reconstrução do espaço pelos reis Bourbons. É possível interpretar a presença desses dois palácios como um tipo de analogia ao "triunfo" e continuidade da casa de Bourbon, e o detrimento da Dinastia Habsburgo no país, representado no próprio palácio em ruínas. Nos retratos reais produzidos por Goya, é possível encontrar diversas referências à antiga dinastia e aos modelos de pintores do período. Um grande exemplo é o próprio Velázquez com seus retratos equestres da família real produzidos em 1635. Destinados ao Salón de Reinos, no palácio de Buen Retiro, esses retratos eram uma afirmação do poder da dinastia e da continuidade de seus membros trono espanhol. Uma das figuras mais interessantes e que deve ter servido de modelo para Coya, é o retrato da Rainha Isabel de Bourbon (figura 6). Existem algumas similaridades importantes com o retrato goyesco, como o céu acinzentado, uma paisagem montanhosa com uma certa vegetação, um tipo de construção bem ao fundo (ainda não identificada pelo autor do texto) e a posição do cavalo, idêntica ao retrato de Maria Luísa, com a pata dianteira dobrada. É interessante notar também a posição das rainhas, que olham diretamente para o espectador virando o rosto em uma posição de meio perfil. Apesar de ser do período Habsburgo, o quadro representa uma rainha proveniente da casa de Bourbon, que se casou com o rei Felipe IV da Espanha na tentativa de uma aliança entre França e Espanha e de dar um herdeiro a Felipe IV. É muito importante frisar, ademais, que Goya, em suas gravuras interpretativas da obra de Velázquez, chegou a reproduzir o retrato da rainha Isabel (figura 7) em 1778, vinte e dois anos antes da produção do retrato de Maria Luísa, o que leva a crer que o seu contato com os retratos de corte de Velázquez havia começado muito antes da preparação para o de Maria Luísa, tendo tempo de refletir e estudar a obra do artista sevilhano a fundo.

Algo que se diferencia realmente do retrato de sua antepassada, é que Maria Luísa se faz representar com uniforme militar, assim como a presença de seu sorriso convencido, algo que não parece ter precedente na pintura para uma rainha espanhola. Mas é interessante notar que apesar da aparente novidade de uma mulher com uniforme militar em um retrato equestre, existiram sim precedentes, inclusive de contemporâneas de Maria Luísa durante o século XVIII. Os retratos de Maria Teresa da Áustria (figura 8) e de Catarina II da Rússia (figura 9); esses retratos são importantes modelos que devem ser levados em consideração, pois existem diversas similaridades nas pinturas e também na vida política das soberanas. Maria Teresa havia subido ao trono depois de uma guerra civil que tentou descartá-la como imperatriz do Sacro Império Romano pelo prevalecimento da 


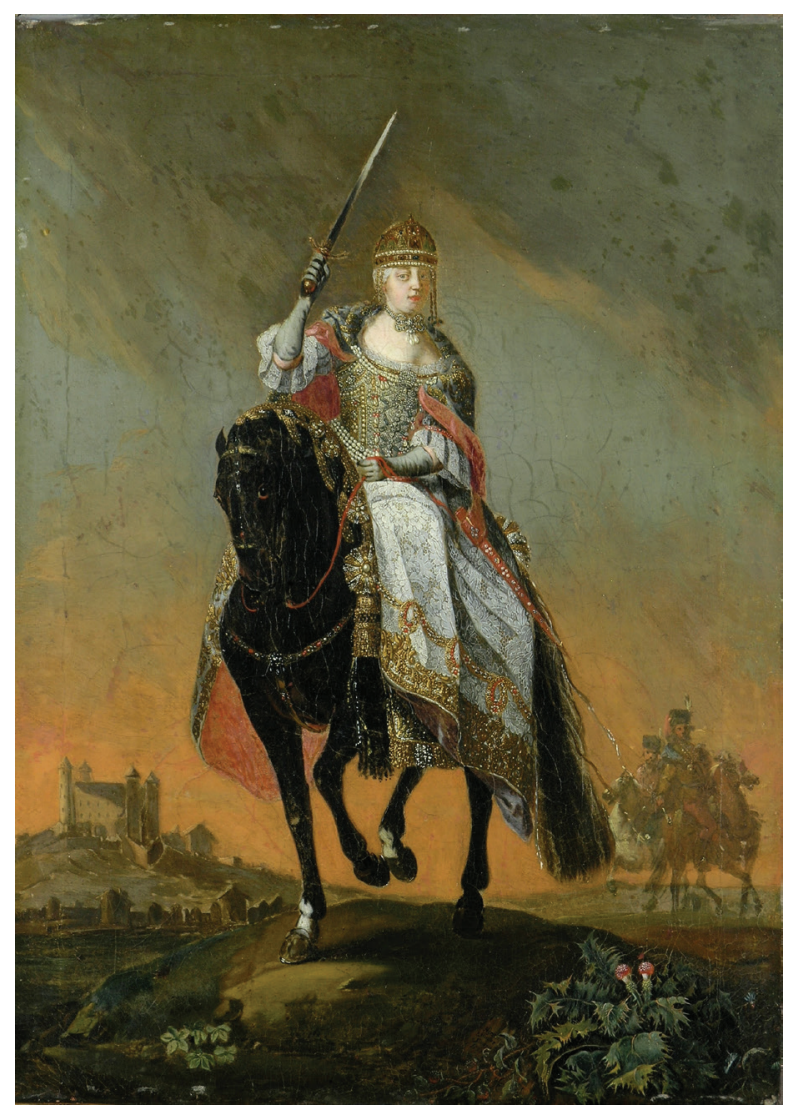

[Figura 8]

C. Hirsch der Jüngere. Der Krönungsritt Maria Theresias in Pressburg (Coroação de Maria Theresa em Pressburg, atual Bratislava), 1747.

Óleo sobre tela, 45.5 × $33 \mathrm{~cm}$. Galéria Mesta, Bratislava.

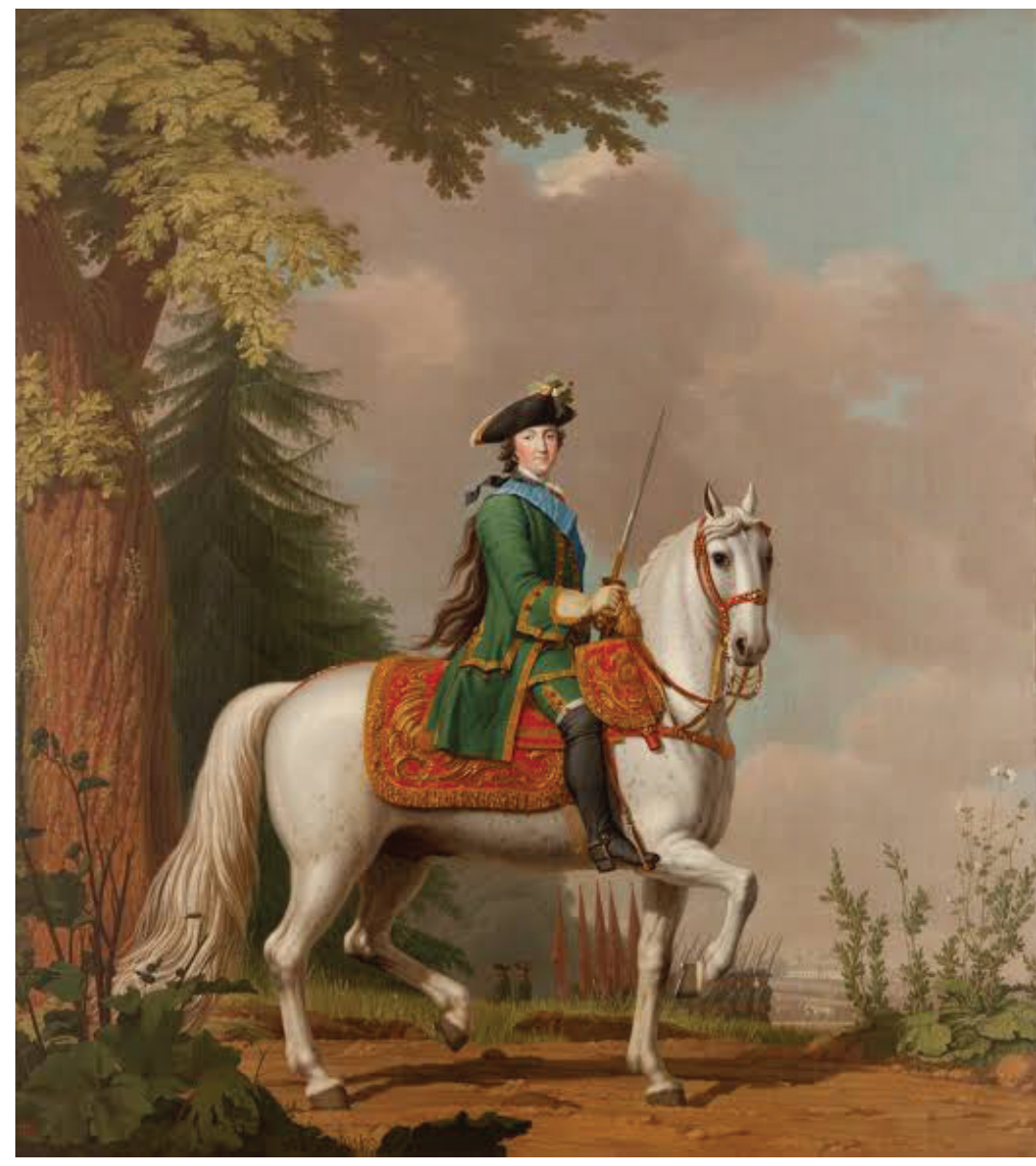

[Figura 9]

Virgilius Ericksen. Retrato equestre de Catarina II, a Grande, 1765.

Óleo sobre tela, 385×356 cm. Palácio Peterhof, São Petersburgo. 
lei sálica, ainda em vigor no império. Para contornar essa situação, a imperatriz austríaca se casou com Francisco de Lorena, que se tornou seu co-governante. Apesar do casamento, quem realmente governava era a imperatriz; isso é demonstrado em seu retrato de coroação, no qual ela é quem usa a coroa da Hungria e segura a espada com a mão direita, símbolos de seu poder. Apesar disso, o retrato equestre da Maria Teresa ainda mantém a posição tradicional das pernas para mulheres no cavalo, cobertas por um longo vestido de coroação que substitui o uniforme militar. Já o retrato de Catarina II produzido por Virgilius Ericksen retrata a monarca russa de forma diferente. A cena se passa diante de uma revista de tropas, com diversos soldados no segundo plano. Assim como Maria Luísa, a czarina russa também usa um uniforme militar verde, típico de regimentos russos, mas seu uniforme é de um corte masculino, não adaptado ao seu corpo feminino, como no caso da rainha espanhola. É interessante notar o contexto em que Catarina se tornou a governante russa, depois de depor seu marido Pedro III e assumir o controle completo do Estado russo.

É possível perceber as diversas camadas que esse retrato possui e que podem ser explicadas como uma resposta à Revolução Francesa, um resgate da tradição de artistas estabelecidos, como Tiziano e Velázquez, assim como uma tendência de demonstrar as mulheres rainhas que detinham o verdadeiro poder em detrimento de seus maridos, como é o caso de Catarina II na Rússia ou de Maria Teresa na Áustria. Observar e dissecar os significados presentes no retrato equestre de Maria Luísa de Parma é compreender um período político conturbado da Espanha e da Europa, um momento em que as monarquias (em especial a espanhola) estavam debilitadas e frágeis e já não conseguiam mais responder aos diversos acontecimentos políticos advindos da Revolução e dos ideais iluministas; ainda assim, viam na arte do retrato uma forma de reconstruir ou reafirmar a sua imagem e dar uma resposta aos movimentos revolucionários que questionavam a ordem Absolutista. Goya foi visto por certos autores como um tipo de "iconoclasta do iluminismo", pintando a feiura dos reis e revelando seus piores aspectos. Talvez essa visão não esteja completamente equivocada, mas é necessário recorrer aos outros elementos no quadro que não apenas à questão da feiura como elemento dominante. Como já foi mostrado, é possível levantar diversas questões decorrentes das camadas de significados desse retrato equestre e acrescentar uma interpretação mais consistente a seu respeito. 


\section{Referências Bibliográficas}

BURKE, Peter. Testemunha Ocular: o uso das imagens como evidência histórica. Tradução Vera Maria Xavier dos Santos. São Paulo: Editora Unesp, 2017.

CASTELNUOVO, Enrico. Retrato e Sociedade na Arte Italiana. Tradução Franklin de Mattos. São Paulo: Companhia das letras, 2006.

GOMBRICH, Ernst Hans. A História da Arte; tradução Álvaro Cabral. Rio de Janeiro: Livros Técnicos e Científicos Editora Ltda., 2012.

HARGREAVES-MAWDSLEY, W. N. Eighteeth-Century Spain 1700-1788: A Political, Diplomatic and Institutional History. London: The Mcmillan press LTD, 1979.

HUGHES, Robert. Goya. Tradução Tuca Magalhães. São Paulo: Companhia das Letras, 2007.

MATURANA, Antonio Calvo. Floriblanca, Anranda, Godoy y El partido de la Reina: la influencia política de Mª Luísa de Parma em los primeiros gobiernos de carlos IV (1788-1796) in La España de Carlos IV, № 28. Revista de Historia Moderna: Universidad de Alicante, 2010.

ROSEMBLUM, Robert. Coya frente a David: la muerte del retrato régio in El Retrato. Barcelona: Círculo de Lectores, 2004. SCHNEIDER, Norbert. A Arte do Retrato. Tradução: Teresa Curvelo. Köln: Taschen, 1997.

WARNKE, Martin. O Artistas de Corte: os antecedentes dos artistas modernos. Tradução Maria Clara Cescato. São Paulo: Editora da Universidade de São Paulo, 2001. 